\title{
Literature Review on Engineering Project Risk Management
}

\author{
Songyan Zhang ${ }^{1, \text { a }}$, Yuxiao Fang ${ }^{2, b}$ \\ 1,2China,Hangzhou City, Zhejiang Province, Xihu District, Liuhe Road No. 318 \\ asyzh201@163.com, b313418963@qq.com
}

\begin{abstract}
Keywords: engineering project; risk management; review
Abstract. Engineering project is the carrier of national fixed assets investment. With the increasing scale and complexity of the project, risk management has become an indispensable part of the project.This paper collected a large number of literature from Western countries and China to analyze engineering project risk management research status, and made a summary and a prospect.
\end{abstract}

\section{Introduction}

Engineering project is the carrier of national fixed assets investment. Enhancing the level of project management can accelerate the growth of the national economy. The project has the characteristics of large scale, long construction period, complex technology, environmental uncertainty, so the project is accompanied by a large number of risks. If these risks can not be protected, it will lead cost overrun, time delay, and even lead to the failure of the entire project. Risk management can be a good solution to the engineering project risk in order to ensure the smooth implementation of the project. Therefore, risk management has become an integral part of the project. In recent years, the domestic and foreign research on engineering project risk management has a clear upward trend, which also means that the domestic and foreign academic have paid more attention to the engineering project risk management.

This paper analysis the current research situation of the domestic and foreign risk management of engineering project through the literature research method system, and then prospect the future of risk management of engineering project.

\section{The West Research Status}

As a new enterprise management discipline, risk management has been widely used in engineering project management.

Risk management is the management method to choose the best risk management technology to eliminate or deal with the risk and use the minimum cost to achieve the maximum security. Risk management originated in the United States, and launched by Solomon Huebner in the University of Pennsylvania at an insurance problem meeting held by the American Management Association in 1930. At this time, risk management is still limited to the theoretical discussion and trial stage in the small part of large enterprises. In $50 \mathrm{~s}$, due to workers in the US steel industry held a general strike and a fire in General Motors caused huge economic losses,risk management has begun to attract enough attention in the American industrial and commercial enterprises, and then risk management has begun to promote.

From 1955 to 1964, the modern academic and professional risk management was born, and then, the research on risk management has gradually become systematization and specialization, risk management has gradually become an independent discipline.

In 1963, "enterprise risk management" published by Mel and Heerqisi marked the research on risk management gradually tends to specialization and systematization. And then probability theory and mathematical statistics technology are applied in the field of risk management research, so that the risk analysis changed into a new subject. It showed risk management moved toward from experience to science. In 1968, Altman proposed a multiple linear decision model. In 1972, D.R.Cox proposed the semi parametric risk model of Cox. In 1980, Ohlson set up a Logistic model to predict the risk of enterprise. In 1984, ZWijewski used Probit model to forecast enterprise risk. 
In October 1986, The International Symposium on risk management in Singapore shows: Risk management has gone to the world and has become the international movement of the whole world. This achievement marked that risk management attached to a new level .

In 1990, Odom at first applied the artificial neural network model to the enterprise risk early warning research. Since 1990s, a new risk management model based on loss (i.e. "value at risk", at Risk Value, referred to as "VaR") has been proposed and gradually raised. VaR has succeeded in making risk quantification and standardization, and has become one of the standards in the field of risk management.

Risk management of engineering project theory research is accompanied with the formation and development of the international construction market. In $50 \mathrm{~s}$ and $60 \mathrm{~s}$, With the post-war reconstruction in the Western society, especially the economic recovery in Western Europe, A large number of large scale hydropower, energy, transportation and construction projects have been built in Europe, Huge investment made project managers pay more and more attention to the cost, schedule, quality risk management, and the complex project environment has added a lot of uncertainty factors to the project. How to quantify the influence of uncertainty on the whole project became a big problem for managers. To this end, scholars have developed and studied a variety of project risk assessment techniques, such as the early project planning review technology, the subsequent sensitivity analysis, the simulation technology and so on. With the continuous production of new evaluation methods, the analysis of the project risk is also become comprehensive and multi-dimensional direction. The earliest successful practical application is "Beihai oil field development project" in Europe in 60s and 70s.

In western countries, the representative journal of the research on the engineering project risk management was published in "International Journal of Project Management", which was sponsored by Butterworth-Heinemann. The journal often published articles about the engineering project risk. The journal of the Engineering project risk also have "Project Appraisal"in England and "Journal of Risk and Uncertainty", "Risk Analysis", "The Engineering Economist" in America. And there are other magazines related to this, such as "Insurance: Mathematics and Economics", "Decision Sciences", "Management Science", "Econometrics"and so on. The main contents of these papers are focused on the development of technical methods and the perfection of the theoretical system. Through theoretical research and discussion and preliminary application in practice for decades, the International Academia had a consistent view on the theory of engineering project risk management, they thought risk management of engineering project is a systematic project. It involves all aspects of project management, including risk identification, estimation, evaluation, control and decision making. The purpose of the project is to reduce the loss and control the cost through the research and control of the project environment uncertainty. And the current debate mainly focused on the risk identification and the risk assessment methods.

\section{China Research Status}

The research on the risk problem in China was from the beginning of the risk decision, it started very late. Shifu Zhou(1980) wrote an article to introduce the methods of risk decision,these methods are Bayesian Method and Topliss Decision Method, and it was the first time to introduce the methods of enterprise risk management from the West. Lian She(1989) proposed financial management theory for the first time, and established the enterprise early warning management system, which Emphasizes that enterprise early warning management is equally important to the successful management of traditional enterprise to the Enterprise strategic objectives. After more than 20 years, China has had some treatises about risk analysis and risk decision, but China didn't have many treatises to discuss the engineering project risk, and the discussion of project risk management was much less. In terms of published works and published papers, risk management of engineering project in China focuses on the control of project schedule and cost. Engineering project risk analysis has been applied to practice in China, such as Three Gorges project, Shanghai metro construction project, Dayawan nuclear power station project and so on. Because of the differences in technical foundation, management, social environment and system, the main contradiction between China and western developed countries in engineering project management is far different. At present, there are serious 
problems of risk management existed in China, such as lack of practical application and Theoretical exploration is not systematic and so on.

From the summary of the research in China and other countries, we can see that: In respect of risk management of engineering project, there is a big gap between the Western developed countries and China in theoretical research and practical application, the level of China is still in the stage of introduction, absorption and digestion, so the economic management science workers should put forward a set of engineering project risk management theories which can understand the reality and solve the practical problems. At the same time, China should also have a detailed empirical analysis of various historical and practical issues, and China should use the detailed experience materials to make a text of the effectiveness of various methods and the scientificalness of various theories.

\section{Conclusions}

Nowadays, risk management of engineering project has been widely used in various engineering fields, and has achieved remarkable results. After many years of research and practice, it is proved that risk management of engineering project is scientific, advanced and operational. Through reading a lot of literature in China and other countries, this paper summarizes the following points:

(1)There are many ways to study risk management of engineering project, but most of them drew lessons from the results of other research fields, especially the knowledge of financial risk management. Whether these methods and ideas that have been validated in other areas are still useful in risk management of engineering project should be further researched.

(2)Risk estimation and evaluation of engineering project is the key element of project risk management. But there is no perfect way to estimate the risk of the project. In the research on engineering project risk is based on the actual risk characteristics of project, and combined with a variety of estimation methods and choose one or more effective methods to use. In the same way, there are some limitations in the method of project risk assessment. Expert scoring method and AHP method are more dependent on the experience of experts, they have more subjectivity; Fault Tree method and Event Tree method should analyze a lot of data and information; The method of Fuzzy Analysis is relatively mature and can directly deal with the uncertainty in the project, but it will be subject to professional knowledge, experience and other subjective impact.

(3)In risk management of engineering project, the literature of research on human's psychology, preference, behavior mode are quite few. In addition to considering political risk, economic risk, management risk, property risk and so on, China also need to take into account the subjective factors such as people's behavior and preference, because people's thinking and behavior will affect the risk decision. Therefore, research on human's subjective factors play a crucial role in engineering project risk decision.

In addition, the research on risk management of project is also given the new great hopes in the future: (1)Establish a more mature risk management of engineering project theory system, through the empirical method to verify the validity and applicability of the theory, at the same time pay attention to the combination of theory and risk management of engineering project. (2) With the continuous development of information and network technology, project risk management will be more dependent on computer. Through the operation function of the large computer platform,managers should simulate implementation process of Simulation engineering project. (3) According to the different behavior characteristics of human, China should establish a perfect risk management risk decision analysis model, and analysis the influence of different people's subjective factors on the probability of risk, so as to make the right risk decision.

\section{Acknowledgements}

This research was financially supported by the National Natural Science Foundation of China (Grant NO. 11171306) and The 2015 cross Pre-research project of Zhejiang University of Science and Technology (Grant NO. 2015JC09Y). 


\section{References}

[1]Collinge W.H., Re-thinking Stakeholder Management in Construction: Theory \& Research Project Perspectives 2012 [M]. The annual Publication of IPMA ,2011

[2]Lemon W.F., Bowitz J., Hackney R., Information systems project failure: A comparative study of two countries [J]. 2002, 10(2):28-40

[3]Meredith J.R., Mantel S.J. Jr., Project management: A managerial approach. New York: John Wiley \& Sons, 2008

[4]Vinten G., The stakeholder manager [J].2000, 28(6):377-383.

[5]Bryde D.J., Volm J.M., Perceptions of owners in German construction projects: congruence with project risk theory [J]. 2009, 27(11):1059-1071.

[6]Wang J., Yuan H., Factors affecting contractors' risk attitudes in construction projects: case study from China [J].2011, 29(2):209-219.

[7]Keil M., Wallace L., Turk D., Dixon-Randall G., Nulden U., An investigation of risk perception and risk propensity on the decision to continue a software development project[J]. 2000,53(2):145-157.

[8]In Chinese, Yongqiang Chen,Wei Gu, project risk management research review [J].No.18 Vol.29, Sep.2012,18:157-160.

[9]Emrah A., Yasemin G., Prediction of risk perception by owners' psychological traits in small building contractors [J]. 2011,29(8):841-852.

[10]In Chinese, Qiming Li, Liyin Shen. Risk effect behavior decision model and analysis in risk management[J]. 2001,10:1-8.

[11]Sitkin S.B., Weingart L.R., Determinants of risky decision-making behavior: a test of the mediating role of the risk perception and propensity [J]. 1995, 38(6):1573-1592.

[12]Tversky A., Alovic P., Kahneman D., The causes of preference reversal [J]. 1990, 80: 204-217.

[13]In Chinese, Shan Gao .Research on risk management of construction project [D]. Tianjin University, 2012.

[14]ZI Sakka.,SM El-Sayegh. Float consumption impact on cost and schedule in the construction industry[J].2007,133(2):124-130.

[15]In Chinese, Yang Cui ,Yongqiang Chen, Bingbing Xu.Research status and Prospect of engineering project risk management [J]. 2015,02:76-80. 